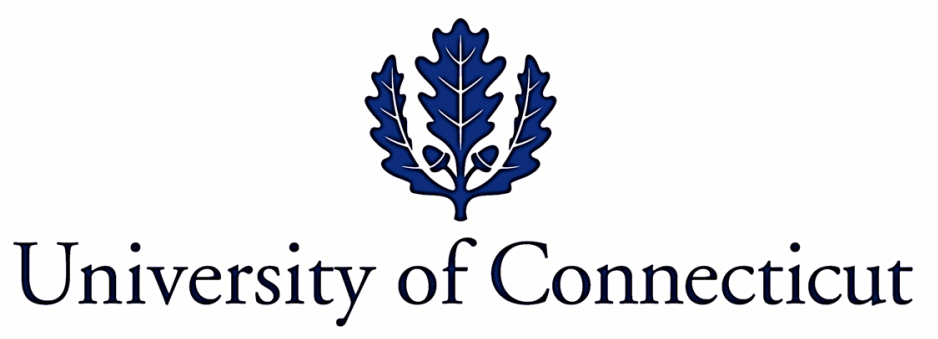

Department of Economics Working Paper Series

\title{
125 Years of Time-Varying Effects of Fiscal Policy on Financial Markets
}

by

Hardik A. Marfatia

Northeastern Illinois University

Rangan Gupta

University of Pretoria

Stephen M. Miller

University of Nevada - Las Vegas

Working Paper 2020-12

August 2020

365 Fairfield Way, Unit 1063

Storrs, CT 06269-1063

Phone: (860) 486-3022

Fax: (860) 486-4463

http://www.econ.uconn.edu/

This working paper is indexed in RePEc, http://repec.org 


\title{
125 Years of Time-Varying Effects of Fiscal Policy on Financial Markets
}

\author{
Hardik A. Marfatia*, Rangan Gupta ${ }^{\dagger}$ and Stephen Miller ${ }^{\ddagger \S}$
}

January 21,2020

\begin{abstract}
This paper examines the effect of fiscal policy on financial markets over a long span of 125 years. Unlike existing studies that mainly focus on monetary policy shocks and model-based identification of fiscal policy shocks, we use a time-varying parameter model to study the effect of fiscal policy with much cleaner and direct identification of fiscal policy shocks. In addition, we extend our analysis by measuring the response volatility in these markets and separately study the effects of good and bad components of volatility. We find significant time-variation in the response of stock and bond market returns and volatility. The overall response of the stock market exceeds that of bond markets, with more pronounced effects in the pre-1950 period than in the last six decades. Fiscal consolidation generates long-term benefits that positively affect financial markets in the latter part of the $20^{\text {th }}$ century, thus providing new insights into the dynamic role of fiscal policy.
\end{abstract}

JEL Classifications: E5, C32, G14

Keywords: Fiscal Policy; Time-Varying impact; Financial returns and risks.

*Department of Economics, Northeastern Illinois University, BBH 344G, 5500 N. St. Louis Ave., Chicago, IL 60625, USA. E-mail: h-marfatia@neiu.edu.

${ }^{\dagger}$ Department of Economics, University of Pretoria, Pretoria, 0002, South Africa. E-mail: rangan.gupta@up.ac.za

${ }^{\ddagger}$ Corresponding author. University of Nevada, Las Vegas - Department of Economics, 4505 S. Maryland Parkway, Box 456005, Las Vegas, NV 89154. Email: stephen.miller@unlv.edu.

$\S$ We would like to thank two anonymous referees for many helpful comments. However, any remaining errors are solely ours. 


\section{Introduction}

Studies that examine the effect of economic policy on movements in U.S. financial markets typically focus on monetary policy. Simo-Kengne et al. (2016) provide a detailed literature review. The emergence of the zero lower bound of the Federal funds rate in the aftermath of the Great Recession precipitated a recent literature that analyzes the effect of fiscal policy on stock markets (Afonso and Sousa, 2011; Agnello and Sousa, 2013; Chatziantoniou et al., 2013; Mumtaz and Theodoridis, 2017; Gupta et al., 2018; El Montasser et al., forthcoming) and bond markets (Tavares and Valkanov, 2001; Ardagna, 2009; Li et.al., 2018). In general, these papers show that expansionary fiscal policy positively affects stock and bond returns.

This paper extends this literature by studying the time-varying effect of fiscal policy shocks (after controlling for standard macroeconomic variables) on not only historical stock and bond market returns of the United States, but also their volatility, over the past 125 years (1890Q1 to 201564). Unanticipated changes in fiscal policy (i.e., a fiscal shock) can influence stock market returns via its effect on sovereign risk spreads, and affect volatility through leverage and trading activity channels (Gospodinov and Jamali, 2018). Following Cooley and Prescott (1976), we model the time-variation as a driftless random walk and estimate using maximum likelihood via the Kalman filter. This approach offers an appealing and flexible way to reveal the time-varying responsiveness of financial market returns and volatility to fiscal policy shocks. Market participants not only care about the nature of volatility but also about its level, where traders clearly distinguish between good and bad volatilities (Caporin et al., 2016). We also analyze the effects of fiscal policy on good and bad components of volatility, besides the overall volatility (variance) of stock and bond returns. Finally, since the stock market probably behaves asymmetrically to positive and negative news (Rigobon and Sack, 2008), we also consider the analysis of the time-varying effects of positive and negative fiscal policy shocks on stock and bond market movements.

Importantly, to obtain accurate statistical inference, we require a measure of the fiscal shock that is not only exogenous to the state of the economy but also unanticipated. Therefore, we use the news series of Ramey and Zubairy (2018), which considers changes in government spending that link to political and military events. Since we rely on a much cleaner identification approach that uses exogenous and unanticipated fiscal policy shocks, we overcome the limitation of the standard approach of identifying fiscal policy shocks using structural vector autoregressive (SVAR) models, ${ }^{1}$ since the shock will also incorporate measurement error in the government spending series (Ramey, 2011). Furthermore, our modeling strategy can also determine the precise time variation in the effect of fiscal policy shocks that occur in a very long span of time.

Over the last 125 years (1890-2015), evidence suggests significant time variation in the effects

\footnotetext{
${ }^{1}$ Ellahie and Ricco (2017) provide a detailed discussion of the issues.
} 
of fiscal policy on different measures of the financial system, with greater effect pre-1950 than post1950. Moreover, positive fiscal policy shocks lead to higher bond and stock returns and generally dampen the volatility in these markets in the later $19^{t h}$ century and early $20^{t h}$ century. The sign of the responses reversed in the latter half of the $20^{t h}$ century. Thus, for most of the post-1950 period, fiscal contraction (expansion), which causes the government's budget position to improve (deteriorate), generally means good (bad) news for financial markets, albeit with significant time variation. The stock market response to fiscal policy shocks generally exceeds the response of the bond markets. In spite of significant time variation, the overall effect of fiscal policy shocks after 1950 has largely trended upward for stock returns and downward for volatility. The TVP plots of good and bad components of realized volatility of both stock and bond markets show that fiscal policy shocks in the early $20^{\text {th }}$ century generated a significantly positive response for good volatility and a negative response for bad volatility. The overall evidence, thus, highlights the dynamic role of fiscal policy in influencing financial markets.

While El Montasser et al. (forthcoming) conduct an analysis of the effect of fiscal policy on historical annual stock returns based on a time-varying parameter SVAR (TVP-SVAR), we believe that this paper is the first to analyze such effects using higher-frequency, quarterly data. We consider the effects of aggregate, positive, and negative government spending shocks on stock and bond returns as well as on volatility and its good and bad components. An analysis of stock and bond market movements at the quarterly, rather than the annual, frequency is important because agents often react quickly to news about government spending and the state of the economy can change abruptly.

\section{Methodology and Data}

\subsection{Methodology}

This paper studies the effect of fiscal policy shocks on stock and bond markets over 125 years (18902015). Obviously, such a long time span has experienced several structural shifts in the effect of fiscal policy on the financial markets. Hence, to determine clearly the effect of fiscal policy, we need to employ a methodology that can deal with structural change. We adopt a time-varying parameter (TVP) framework to meet this objective. One advantage of a TVP model is that it is flexible and yet clearly discerns the pattern of fiscal policy effects over time. In particular, for each $i$ component of the stock and bond markets, we estimate

$$
R_{t}^{i}=\beta_{0 t}^{i}+\beta_{1 t}^{i} F P_{t}+\beta_{2 t}^{i} M P_{t}+\beta_{3 t}^{i} \text { Macro }_{t}+e_{t}^{i} \text { where, } e_{t}^{i} \sim N\left(0, \sigma_{e}^{i}\right)
$$




$$
R_{t}^{i}=\left[\begin{array}{llll}
c & F P_{t} & M P_{t} & \text { Macro }_{t}
\end{array}\right]\left[\begin{array}{c}
\beta_{0 t}^{i} \\
\beta_{1 t}^{i} \\
\beta_{2 t}^{i} \\
\beta_{3 t}^{i}
\end{array}\right]+e_{t}^{i}
$$

where, $F P_{t}$ measures the fiscal policy shock at time $t ; M P_{t}$ controls for possible monetary policy stance at time $t$; and Macro $_{t}$ controls for macroeconomic conditions at time $t$. The monetary policy stance $\left(M P_{t}\right)$ is measured by the changes in the short-term Treasury bill rate and the macroeconomic conditions $\left(\mathrm{Macro}_{t}\right)$ are measured by the first principal component extracted from real GDP growth, the inflation rate, and the unemployment rate. ${ }^{2}$ Here, $i$ refers to different components of the financial market namely, bond market returns, their realized volatility, good realized volatility, and bad realized volatility as well as stock market returns, their realized volatility, good realized volatility, and bad realized volatility.

Our parameter of interest is $\beta_{1 t}$ as it measures the time-varying effect of fiscal policy shocks on one of the $i$ components of the stock and bond market, after controlling for the monetary policy and the macroeconomic environment prevailing at each point in time. The expected sign for $\beta_{1 t}$ varies across components. Fiscal policy shock probably exerts a positive effect on stock and bond market returns. One can also argue that higher spending by the government would worsen budget deficits and that this could exert negative effects on stock and bond returns. For the volatility components, the sign may be positive (indicating positive fiscal shocks increase risks and volatility in the financial markets) or negative (indicating higher government spending improves economic conditions and reduces financial market volatility). Also, notice that by controlling for the monetary policy stance and the macroeconomic environment, the coefficient $\beta_{1 t}^{i}$ provides the direct effect of fiscal policy on stock and bond markets.

To allow time-variation, we assume that $\beta_{t}^{i}$ follows a random walk. Thus, the transition equation representing the evolution of the unobserved state vector is then given by:

$$
\begin{gathered}
\beta_{t}^{i}=\beta_{t-1}^{i}+v_{t}^{i} \text { where, } v_{t}^{i} \sim N(0, Q) \\
{\left[\begin{array}{c}
\beta_{0 t}^{i} \\
\beta_{1 t}^{i} \\
\beta_{2 t}^{i} \\
\beta_{3 t}^{i}
\end{array}\right]=\left[\begin{array}{llll}
1 & 0 & 0 & 0 \\
0 & 1 & 0 & 0 \\
0 & 0 & 1 & 0 \\
0 & 0 & 0 & 1
\end{array}\right]\left[\begin{array}{l}
\beta_{0 t-1}^{i} \\
\beta_{1 t-1}^{i} \\
\beta_{2 t-1}^{i} \\
\beta_{3 t-1}^{i}
\end{array}\right]+\left[\begin{array}{c}
v_{0 t} \\
v_{1 t} \\
v_{2 t} \\
v_{3 t}
\end{array}\right]}
\end{gathered}
$$

where, $Q$ represents the variance-covariance matrix of the uncorrelated disturbance terms. The Kalman filter is applied to the above state-space model and the parameters are estimated using

\footnotetext{
${ }^{2}$ This is a parsimonious and yet an effective approach of measuring macroeconomic environment as compared to including each individual macroeconomic variable in the estimation process.
} 
maximum likelihood.

Our approach has several merits. First, in contrast to alternative approaches of modeling timevariation like structural breaks and Markov switching, our approach overcomes the problem of distinguishing between different forms of time-variation. Moreover, structural break models are merely special cases of the TVP model (Boivin, 2006). ${ }^{3}$ Second, our approach allows for a gradual evolution of the financial markets response to fiscal policy shocks. This partially addresses the problem of potentially non-normal distribution usually argued to be present in the case financial asset returns. ${ }^{4}$ In particular, the use of the state space framework for estimating the TVP model provides the advantage of the Kalman filter and the iterative process. That is, the prediction of the unobserved state (TVP in the present case) is updated based on the Kalman gain made from the new information received at each stage of estimation (i.e., at each period). Hence, even if one ignores the extreme movements that generate non-normal distribution, the overall inference will remain largely unaffected. The only effects, if any, could be that some of the extreme sharp spikes in the plots may be replaced by smoother transition. We believe, however, that it is necessary to capture the extreme movements given the very nature of financial markets.

One limitation of the TVP model that can affect the inference is the curse of dimensionality. In general, using the maximum likelihood (ML) method for a large dataset with multiple variables can prove computationally burdensome. The inability to find the maximum and presence of multiple local equilibria can lead to the actual or perceived instability in the estimates. This is particularly true when both the coefficients and the variance-covariance matrix are modeled as time-varying. In the present case, though we use 125 years of data, the model specification is parsimonious and these limitations, thus, do not apply.

\subsection{Data}

Our raw data include the S\&P 500 total return index, the 10-year government bond total return index, real Gross Domestic Product (GDP), the GDP deflator, the unemployment rate, and the 3month Treasury bill rate, in addition to the government spending shock. The S\&P 500 and 10year government bond total return indices are available at a monthly frequency from the Global Financial Database, which we convert to quarterly log-returns and realized volatility. Following Andersen and Bollerslev (1998), we define realized volatility as the sum of squared monthly returns over a quarter, with good realized volatility only involving the sum of squared positive monthly returns, and bad realized volatility only including the sum of squared negative monthly returns.

\footnotetext{
${ }^{3}$ For detailed merits of the TVP model, see Stock and Watson (2002) and Boivin (2006).

${ }^{4}$ The concerns of potentially non-normal distribution are also mitigated in our case because fewer than $5 \%$ of observations lie above or below 2 standard deviations. This is the advantage of analyzing 125 years of data. Hence, any tail effects will be minimal, especially given the advantages of Kalman filter in the present case. Further, the analysis is done at a quarterly frequency. Movements in stocks and bonds that produce non-normal distribution are far more prevalent at daily or weekly frequencies.
} 
The remaining variables come from the dataset posted at the website of Professor Valery A. Ramey: https://econweb.ucsd.edu/ vramey/research.html\#data.

Ramey and Zubairy (2018) construct the news series as changes in the expected present discounted value of government spending. The fiscal policy shock equals the nominal value divided by the one-quarter lag of the GDP deflator times trend real GDP. We use exactly this variable in our study as a measure the fiscal policy shock. Ramey and Zubairy (2018) estimate the real GDP time trend as a sixth-degree polynomial for the logarithm of GDP, from 1889G1 through 2015Q4, excluding 1930Q1 through 1946Q4. In this regard, these authors follow Gordon and Krenn (2010), who illustrated the problems that arise when one uses standard filters to estimate trends during samples that involve the Great Depression and World War II. Given this, Gordon, and Krenn (2010) advocated the use of a piecewise exponential trend based on benchmark years, and the procedure followed by Ramey and Zubairy (2018) is a smoothed version of theirs.

The identification of fiscal policy shocks has recently received significant attention in the literature. The challenge is that the identification of fiscal policy shocks should not only be holistic but also be clean and precise. As Ramey (2016) noted, the main identification schemes include SVARs with contemporaneous restrictions, sign restrictions, medium horizon restrictions, narrative methods, and estimated DSGE models. In contrast to the existing model-based identification approaches, the identification scheme used in this paper is much more holistic, cleaner, and precise. It recognizes the state-dependence of shocks, which becomes particularly relevant at the zero lower bound condition on interest rates. This makes the shocks more holistic than other identification strategies. Further, identification of fiscal policy shocks is cleaner because the shocks are both exogenous and unanticipated. And lastly, the shocks are constructed independently from the news sources and, hence, are less sensitive to measurement error (Ramey and Zubairy, 2018). A more detailed discussion of these issues appears in Ellahie and Ricco (2017).

Table 1 provides summary statistics of the data. Table 1 shows that the average positive fiscal policy shock (6.13) exceeds in magnitude the average negative fiscal policy shock (-4.90). This implies that the government has, on average, over-spent in the last 125 years. This outcome is intuitive, since the large spending to finance World War I and II and also the attempt of the government to fight the Great Depression of the 1930s and the Great Recession of 2008-2009. An overview of 125 years of the two most important components of the financial markets - stocks and bonds - also reveal interesting behavior. In contrast to conventional financial wisdom of the riskreturn relationship between the stock and bond markets, the results show that the average return on both the stock and bond markets over the last 125 years is nearly the same. The mean realized volatility of the stock market (17.90), however, exceeds the average realized volatility in the bond market (2.81). This is also intuitive as we would expect stock markets to be riskier than the bond markets. 


\section{Fiscal History and Empirical Results}

Given the long time period of this study, a brief overview of fiscal history would provide intuitive support to the empirical results. An understanding of the overall pattern of government revenue and spending will provide the background to evaluate the 125 years of time-varying effects of fiscal policy on financial markets.

\subsection{Fiscal History}

We can call the history of fiscal activity at the federal level in the United States, a $20^{\text {th }}$ century story. That is, government revenue and spending in the United States as a fraction of GDP did not play an important role until the post-WWII period. Both revenue and spending by the government averaged around 3-percent of GDP prior to WWII.

Exceptions to this rule occurred on the spending side, where shocks to fiscal spending jumped as a fraction of GDP to significantly above its trend during the Civil War, WWI, WWII, and the Korean War. Spending prior to WWII generally funded defense and interest on the debt. Since interest on the debt largely helped to fund defense, we can say that defense spending dominated federal spending before WWII. After WWII, spending became much more a function of health care and social security spending along with defense spending.

On the revenue side, tariff and excise tax revenue provided most of the funding for government operations prior to WWII. Revenue, as noted above, stayed in the 3 percent of GDP range until WWII. The personal and corporate income taxes did not emerge as important sources of revenue until WWII. Now, these two income taxes and the social security tax provide most of the revenue flowing to the federal government.

Prior to WWII, the government would grow in its size as a fraction of GDP during wars, but then dissipate in size after the war. That did not happen in the aftermath of WWII. The buildup in WWII saw the biggest increase in the size of the federal government in U.S. history and the size of government did not back off after WWII. Government revenue now averages in the range just below 20-percent of GDP, while government spending now averages in the range of just slightly below or slightly above 20-percent of GDP.

While this paper focuses on the effects of fiscal policy, the historical developments on the monetary policy front are also worth noting. The break date occurs after WWII and at the implementation of the Federal Reserve-Treasury Accord of 1951. During our first subsample from 1890 to 1950, the Federal Reserve entered the scene in 1913, but took considerable time to discover and begin implementing its policy levers. For example, open market operations did not really become a tool until after the experience of the Great Depression. 
Our sample runs from 1890 through 2015. Thus, our sample includes one period when fiscal policy played a small role as a percentage of GDP and another period when fiscal policy played a much more important role. At the same time, the shocks to fiscal policy saw dramatic effects during the time period when fiscal policy was a small percentage of GDP. On the other hand, monetary policy's main tools become operational until after the experience of the Great Depression. In discussing and presenting the results, we keep this key historical perspective in mind.

\subsection{Empirical Results}

Figures 1-4 show the time-varying effects of fiscal policy on different aspects of stock and bond markets, after controlling for changes in the monetary policy stance and the macroeconomic environment. Note that even though we estimate the process for the whole sample period from 1890 to 2015, considering fiscal history discussed above, we segment the presentation of results for the 1890-1950 and 1951-2015 periods. The very long time span necessitates doing so given our findings that the effect of fiscal policy varies significantly over time. This supports the main thesis of the paper. Moreover, since the coefficients magnitudes are larger in the pre-1950s relative to the post-1950s, plotting the time-varying paths separately for these two periods gives the reader an easier time in observing variations over time. This split-point of whole sample is also guided by the evolution of fiscal history in the U.S. noted above.

Several overall patterns and observations emerge from Figures 1-4 and Appendices A and B. First, significant time variation exists in the effects of fiscal policy on different measures of the financial system. The time-varying effect of fiscal policy on bond and stock returns and their volatilities range much wider in the 1890 to 1950 sub-period relative to the 1951 to 2015 sub-period. The exceptions are the response of stock return volatility and bad volatility to a negative fiscal policy shock. Further, between 1890 to 1950, bond and stock returns and their volatilities exhibited much movement in the 1890 to 1915 portion of the sub-period and then stabilized. The observed finding that effects prove larger in the pre-1950s than in the post-1950s largely reflects the presence of World War I and II and the Great Depression, which supported Keynesian-type government spending. The results show that such significant events and the fiscal response to these events caused a significant movement in the financial markets. While the post-1950s also witnessed some big

events such as the recent financial crisis, the results suggest that the effects of fiscal policy shocks on financial markets, on average, were lower in magnitude in the post-1950s.

Second, even while the coefficients' magnitudes are larger in the pre-1950s compared to the post-1950s, sizable time-variation exists in fiscal policy effects in the second half of $20^{\text {th }}$ century. The fiscal history of revenue and spending patterns intuitively explain this outcome. Note that prior to WWII, the government size as a fraction of GDP grew during wars, but then it dissipated after 
the war. Consequently, the financial markets response to fiscal shocks during this time period was mostly centered around war periods. In the post-1950s, however, the financial system responded with greater time variation as fiscal spending became an economic driver with health care, social security, and other fiscal spending in addition to defense spending.

Third, in the 1951 to 2015 period, we observe significant changes in the time-varying effect of fiscal policy for bond and stock returns and their volatilities around 1980. Moreover, for negative fiscal policy shocks, significant changes occur around 1985. Both of these dates fall into the estimates of the beginning of the Great Moderation in the United States. Moreover, the 1978 to 1980 period associates with the Iranian revolution and the first Iran-Iraq war, and the 1981 to 1986 period associates with a dramatic decline (collapse) in oil prices.

Broadly, we find that positive fiscal policy shocks lead to higher bond and stock returns and generally dampens the volatility in these returns. This is particularly true in the pre-1950s. This corroborates the existing evidence relating to stock markets (Tavares and Valkanov, 2001; Ardagna, 2009; Afonso and Sousa, 2011; Agnello and Sousa, 2013; Mumtaz and Theodoridis, 2017; Gupta et al., 2018; and El Montasser et al., forthcoming). For most of the post-1950s, the coefficient of the fiscal policy's effect on stock and bond returns is negative. The episodes of fiscal contraction (expansion), which cause the government's budget position to improve (deteriorate), generally signal good (bad) news for financial markets, albeit with significant time variations. That is, the financial markets have generally welcomed the fiscal consolidation process and its long-term benefits in the latter part of the $20^{\text {th }}$ century.

These dynamics reveal at least two important features of fiscal policy's effects over the last 125 years. First, the results show significant time variation in the stock and bond market returns and their volatility responses to fiscal policy shocks. Thus, the fixed coefficient approach that most existing studies employ measures the effects, on average. This assumption proves highly restrictive when the data speak for themselves. Second, the results highlight the importance of the flexible framework of the TVP model used in the paper. This approach uncovers the dynamic role of fiscal policy in influencing the financial markets.

Interesting insights also emerge from studying the individual time-varying responses of different aspects of the bond (Figs. 1 and 2) and stock markets (Figs. 3 and 4). Figure 1 shows that the effects of fiscal policy shocks on bonds market volatility vary more and with a greater magnitude relative to the response of bond returns in the post-1950s. In addition, the response of realized volatility in the bond market varied more in the post-1950s than the pre-1950s. That is, fiscal policy shocks exerted more varied effects on bond market risks in the last six decades. One possible explanation for this behavior could be the increased depth and maturity of the bond markets in the recent past as compared to the more shallow and less sophisticated bonds market of the early $20^{\text {th }}$ century. At the same time, the fiscal shocks exerted much larger effects on bond returns in the pre-1950s 
compared to the post-1950s. This also could reflect the shallowness of the bond market in the pre-1950s.

Figure 2 plots the time-varying response of good and bad components of realized volatility in the bond markets. The fiscal policy shocks in the late $19^{t h}$ century and the early $20^{t h}$ century initiated a significantly positive response in the good volatility (Fig. 2(a)) and a negative response in the bad volatility (Fig. 2(c)). This highlights the success of fiscal policy shocks in that period. In the post-1950 era, the fiscal policy caused smaller time variation in the response of the good component of realized volatility in the bond markets (Fig. 2(b)) compared to the bad component of realized volatility (Fig. 2(d)). In addition, the good component of realized volatility deviated from zero more frequently (Fig. 2(b)) than the bad component of realized volatility (Fig. 2(d)).

Figure 3 shows the time-varying effects of fiscal policy shocks on stock market returns and volatility. The evidence in Figure 3 suggests that in spite of significant time variation, the effects of fiscal policy on stock returns in the post-1950s, although negative, largely trended upward toward zero (Fig. 3(b)), while a positive and downward trending effect on volatility occurs in the same period (Fig. 3(d)). Moreover, the magnitude and variation of the effects on stock returns (Fig. 3(a)) and volatility (Fig. 3(c)) exhibited larger values in the later $19^{\text {th }}$ and early $20^{\text {th }}$ centuries compared to the last six decades. We also observe such patterns in the pre-1950s. The time variation in the effect of fiscal policy shocks was lower on good (Fig. 4(a)) and higher on bad (Fig. 4(c)) components of realized volatility. Finally, the effects of fiscal policy shocks on bad volatility (Fig. 4(d)) exceed those on good volatility (Fig. 4(b)).

Rigobon and Sack (2008) argue that the stock market probably behaves asymmetrically to positive and negative news. Hence, we also analyze individually the time-varying effects of positive and negative fiscal policy shocks on different measures of bond and stock market movements. We estimate all the models for positive fiscal policy shocks and then redo the estimation for negative shocks. ${ }^{5}$ To compare the results, we compute the correlation coefficient between the TVP of overall fiscal policy shocks and the TVP of positive and negative shocks. These results appear in Table $2 .{ }^{6}$ The results show that the effects of positive fiscal policy shocks are similar to the overall effects of shocks. The correlation is positive and above 0.9 in each case. In other words, the effects of overall shocks dominate, in principle, the higher spending by the government. The same does not hold for the effects of negative shocks, where we find a much weaker correlation, which sometimes turns negative.

\footnotetext{
${ }^{5}$ For robustness of results, we also estimated models by including both positive and negative together in one specification. The results are robust to this change. In each case, the TVP estimates obtained from separately considering positive and negative shocks correlate exactly (correlation coefficient is 0.99) with the TVP estimates obtained by including both positive and negative shocks together in one specification. These results are available upon request.

${ }^{6}$ For brevity, individual TVP plots appear in the Appendix for different measures of stock and bond markets responses to positive (Appendix A) and negative (Appendix B) fiscal policy shocks.
} 


\section{Conclusion}

This paper examines 125 years of time-varying effects of fiscal policy shocks on stock and bond market returns and volatilities. To capture all the structural changes to the economy in such long time span, we use a flexible time-varying parameter framework. We combine this with a much cleaner identification of fiscal policy shocks that prove both exogenous and unanticipated. This contrasts to the existing literature, which mainly focuses on monetary policy or uses modelbased identification of fiscal policy shocks and which mostly limits the analysis to far shorter time span. Furthermore, we also separately measure the effects of fiscal policy shocks on good and bad components of realized volatility of the stock and bond markets.

Significant time variation exists in the financial market's response to fiscal policy shocks, with the stock market responding more than bond markets. The effects of fiscal policy shocks are far more pronounced in the pre-1950s than in the last six decades. Further, the evidence suggests that financial markets have generally welcomed the process of fiscal consolidation and its long-term benefits in the latter part of the $20^{t h}$ century. These results provide new insights into the dynamic role of fiscal policy in influencing financial markets. 


\section{References}

Afonso, A., and Sousa, R. M., (2011). What are the effects of fiscal policy on asset markets? Economic Modelling, 28(4), 1871-1890.

Agnello, L., and Sousa, M., (2013). Fiscal policy and asset prices. Bulletin of Economic Research, 65(2), 154-177.

Andersen T.G., and Bollerslev T. (1998). Answering the Skeptics: Yes, Standard Volatility Models Do Provide Accurate Forecasts. International Economic Review, 39 (4), 885-905.

Ardagna, S. (2009). Financial markets behavior around episodes of large changes in the fiscal stance. European Economic Review, 53(1), 37-55.

Boivin, Jean. (2006). Has U.S. Monetary Policy Changed? Evidence from Drifting Coefficients and Real-Time Data. Journal of Money, Credit and Banking, 38 (5): 1149-1174.

Caporin, M., Rossi, E., and Santucci de Magistris, P. (2016). Volatility jumps and their economic determinants. Journal of Financial Econometrics, 14(1), 29-80.

Chatziantoniou, I., Duffy, D., and Filis, G. (2013). Stock market response to monetary and fiscal policy shocks: Multi-country evidence. Economic Modelling, 30(1), 754-769.

Cooley, T.F., and Prescott, E.C. (1976). Estimation in the presence of stochastic parameter variation. Econometrica, 44(1), 167-184.

El Montasser, G., Gupta, R., Jooste, C., and Miller, S.M. (Forthcoming). The time-series linkages between US fiscal policy and asset prices. Public Finance Review.

Ellahie, A., and Ricco, G. (2017). Government Spending Reloaded: Informational Insufficiency and Heterogeneity in Fiscal VARs. Journal of Monetary Economics, 90, 13-27.

Gordon, R.J., and Krenn, R. 2010. The End of the Great Depression: VAR Insight on the Roles of Monetary and Fiscal Policy. NBER Working Paper No. 16380.

Gospodinov, N., and Jamali, I. (2018). Monetary policy uncertainty, positions of traders and changes in commodity futures prices? European Financial Management, 24(2), 239-260.

Gupta, R., Lau, C-K-M., Miller, S.M., and Wohar, M.E. (2018). US Fiscal Policy and Asset Prices: The Role of Partisan Conflict. International Review of Finance. DOI: https://doi.org/10.1111/irfi.12188.

Li, E. X., Zha, T. A., Zhang, J., and Zhou, H. (2018). Active Monetary or Fiscal Policy and Stock-Bond Correlation. Available at SSRN 3106141.

Mumtaz, H., and Theodoridis, K. (2017). Fiscal Policy Shocks and Stock Prices in the United States. School of Economics and Finance, Queen Mary University of London, Working Paper No. 817.

Ramey, V.A. (2011). Identifying Government Spending Shocks: Its all in the Timing. The Quarterly Journal of Economics, 126(1), 1-50. 
Ramey, V.A., and Zubairy, S. (2018). Government Spending Multipliers in Good Times and in Bad: Evidence from U.S. Historical Data. Journal of Political Economy, 126(2), 850-901.

Rigobon, R., and Sack, B. (2008). Noisy Macroeconomic Announcements, Monetary Policy, and Asset Prices, in Campbell, J.Y. edited Asset Prices and Monetary Policy, 335-370, Chicago University Press, Chicago, USA.

Simo-Kenge, B.D, Miller, S.M. Gupta, R., and Balcilar, M. (2016). Evolution of monetary policy in the US: The role of asset prices. Journal of Real Estate Finance and Economics, 52(3), 226-243.

Stock, James H. and Mark W. Watson. (2002). Has the Business Cycle Changed and Why? Working Paper 9127, National Bureau of Economic Research.

Tavares, J., and Valkanov, R. I. (2001). The neglected effect of fiscal policy on stock and bond returns. In EFA 2003 Annual Conference Paper (No. 201). 
Table 1: Summary Statistics

The table provides summary statistics of the data used in the paper. The fiscal policy shocks are measured in millions of USD and equals the nominal value divided by the one-quarter lag of the GDP deflator times trend real GDP.

\begin{tabular}{l|rrrrrr}
\hline Variables & Mean & Median & Max & Min & S.D. & Obs \\
\hline FP Shock & 1.23 & 0.00 & 739.30 & -507.60 & 57.42 & 504 \\
FP Shock (Negative) & -4.90 & 0.00 & 0.00 & -507.60 & 39.67 & 504 \\
FP Shock (Positive) & 6.13 & 0.00 & 739.30 & 0.00 & 40.79 & 504 \\
Bond Returns & 0.38 & 0.28 & 6.02 & -3.61 & 1.05 & 504 \\
Bond RV & 2.81 & 0.89 & 53.80 & 0.01 & 5.47 & 504 \\
Bond RV Bad & 0.84 & 0.04 & 28.21 & 0.00 & 2.25 & 504 \\
Bond RV Good & 1.97 & 0.42 & 53.80 & 0.00 & 4.94 & 504 \\
Stock Returns & 0.39 & 0.74 & 18.30 & -18.30 & 3.02 & 504 \\
Stock RV & 17.90 & 8.63 & 589.98 & 0.11 & 42.34 & 504 \\
Stock RV Bad & 9.15 & 1.01 & 376.72 & 0.00 & 30.46 & 504 \\
Stock RV Good & 8.75 & 3.79 & 589.98 & 0.00 & 31.24 & 504 \\
T-Bill Rate & 3.55 & 3.34 & 15.05 & 0.01 & 2.65 & 504 \\
Unemployment rate & 6.63 & 5.60 & 24.81 & 0.65 & 4.01 & 504 \\
Inflation & 0.61 & 0.56 & 9.47 & -7.89 & 1.59 & 504 \\
RGDP Growth & 0.80 & 0.81 & 8.19 & -8.77 & 2.26 & 504 \\
\hline
\end{tabular}


Table 2: Correlation between TVP of Fiscal Policy Shocks

The table presents the correlation coefficient between the TVP of overall fiscal policy shocks and the TVP of positive and negative shocks for each measure of stock and bond markets, which include returns, realized volatility (RV), good component of realized volatility (RVG), and bad component of realized volatility (RVB).

\begin{tabular}{l|cc}
\hline TVP of all FP shocks & TVP of positive FP shocks & TVP of negative FP shocks \\
\hline Bond Return & 0.98 & -0.51 \\
Bond RV & 0.98 & 0.78 \\
Bond RVG & 0.90 & -0.27 \\
Bond RVB & 0.99 & -0.73 \\
Stock Return & 0.99 & -0.54 \\
Stock RV & 0.98 & 0.17 \\
Stock RVG & 0.97 & 0.23 \\
Stock RVB & 0.98 & 0.57 \\
\hline
\end{tabular}




\section{Figure 1: Time-Varying Impact of Fiscal Policy on Bond Market}

The figures show the time-varying impact of fiscal policy on the bond market returns and realized volatility.

BOND RTN FP ALL

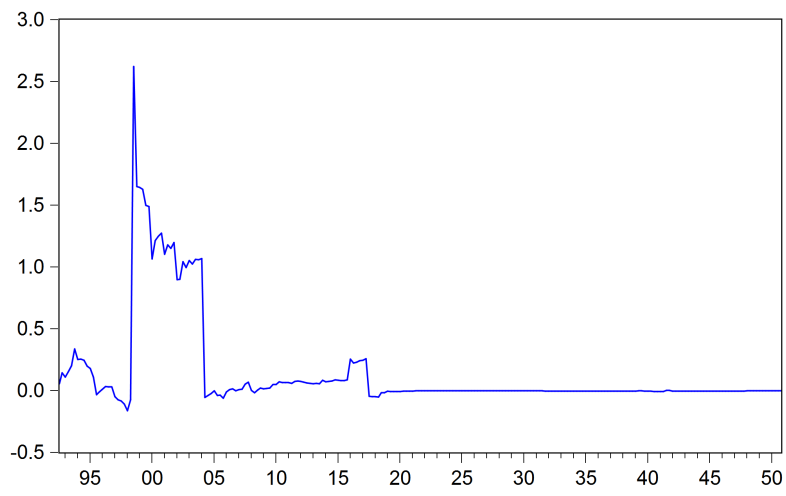

(a) Bond Return (1890-1950)

BOND_RV_FP_ALL

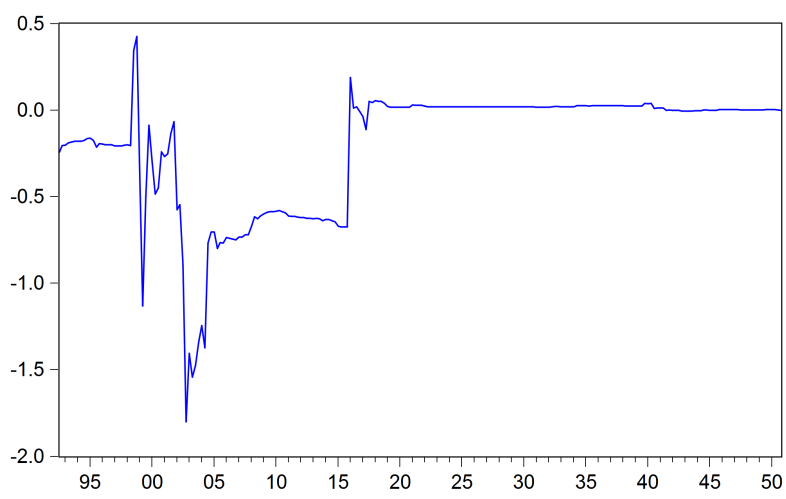

(c) Bond Volatility (1890-1950)
BOND_RTN_FP_ALL

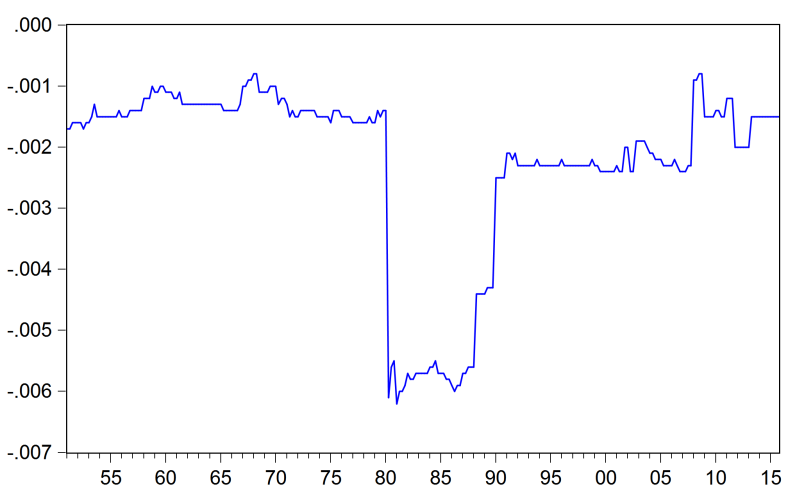

(b) Bond Return (1951-2015)

BOND_RV_FP_ALL

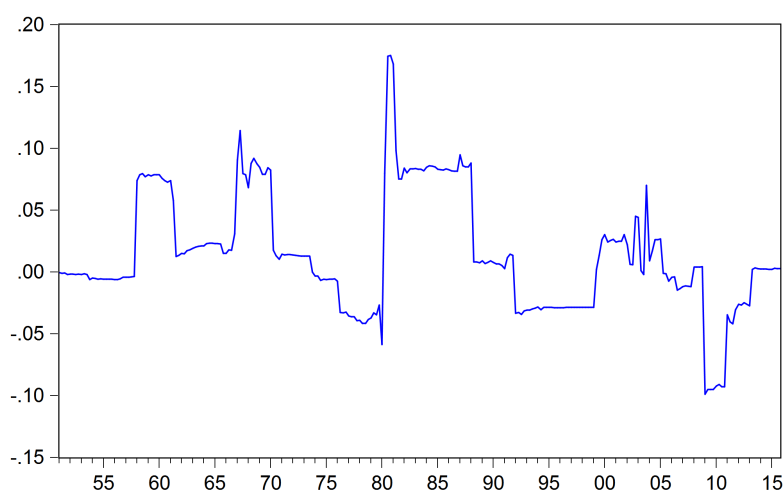

(d) Bond Volatility (1951-2015) 
Figure 2: Time-Varying Impact of Fiscal Policy on the Components of Bond Market volatility

The figures show the time-varying impact of fiscal policy on good and bad components of the bond market volatility.

BOND RVG FP ALL

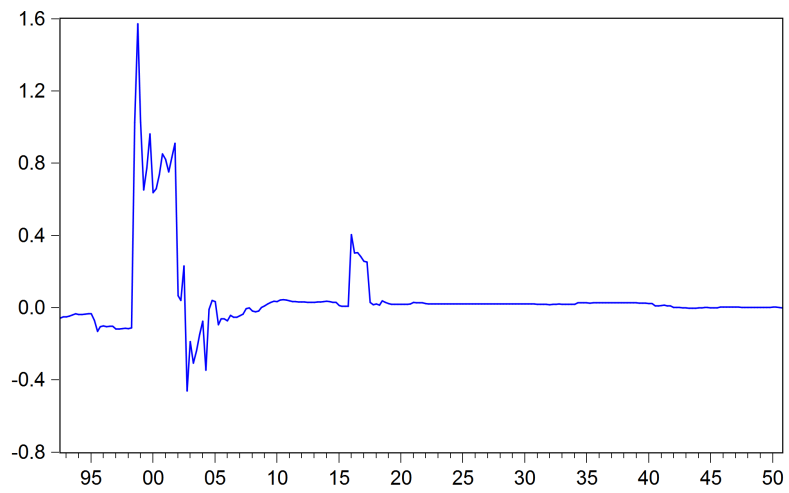

(a) Bond Volatility Good (1890-1950)

BOND_RVB_FP_ALL

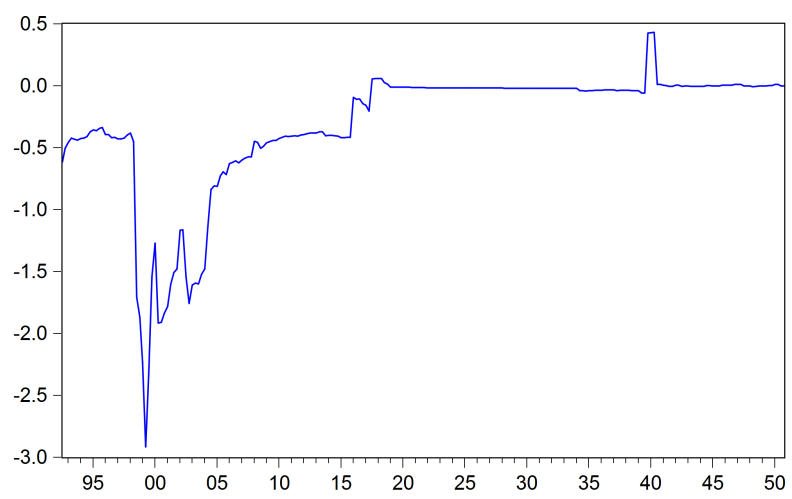

(c) Bond Volatility Bad (1890-1950)
BOND RVG FP ALL

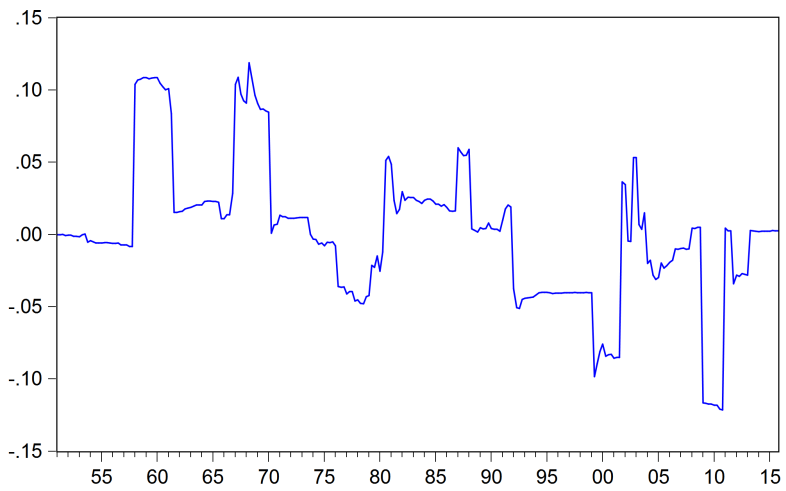

(b) Bond Volatility Good (1951-2015)

BOND_RVB_FP_ALL

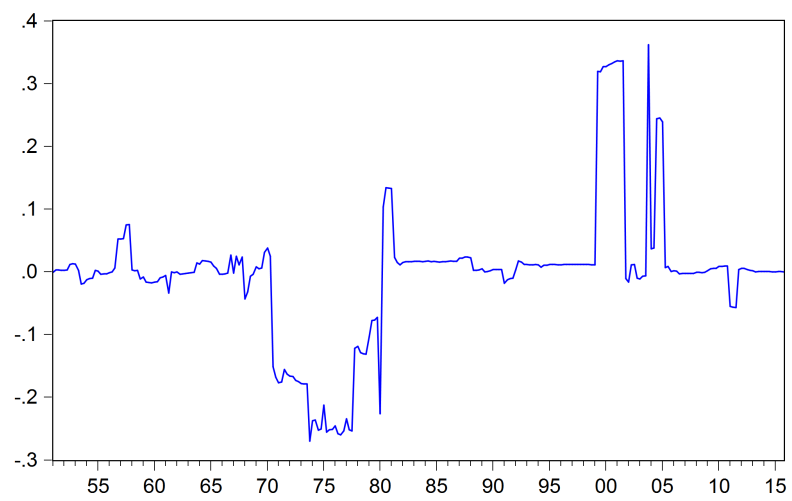

(d) Bond Volatility Bad (1951-2015) 


\section{Figure 3: Time-Varying Impact of Fiscal Policy on Stock Market}

The figures show the time-varying impact of fiscal policy on the Stock market returns and realized volatility.

STOCK RTN FP ALL

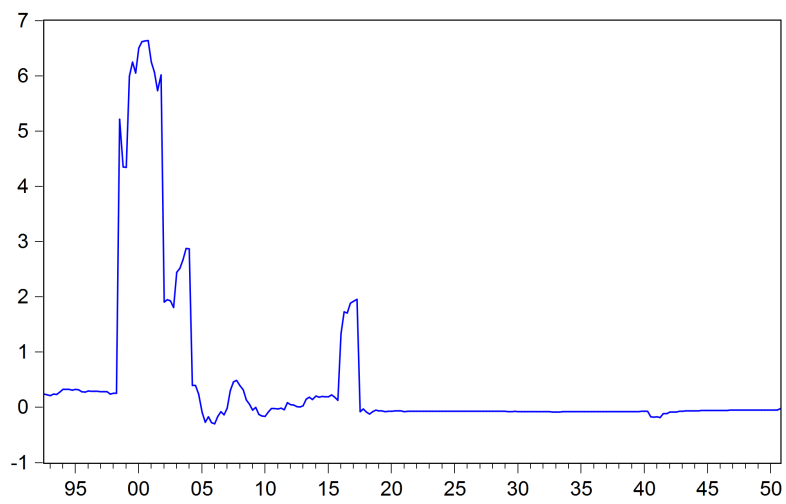

(a) Stock Return (1890-1950)

STOCK RV FP ALL

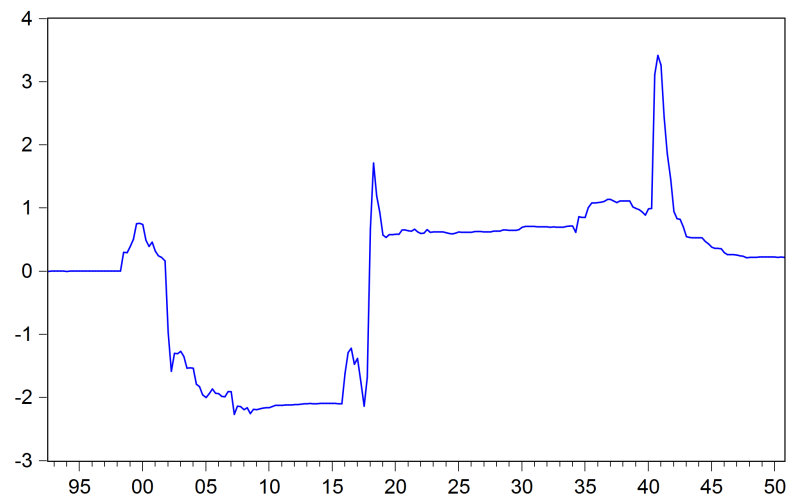

(c) Stock Volatility (1890-1950)
STOCK_RTN FP ALL

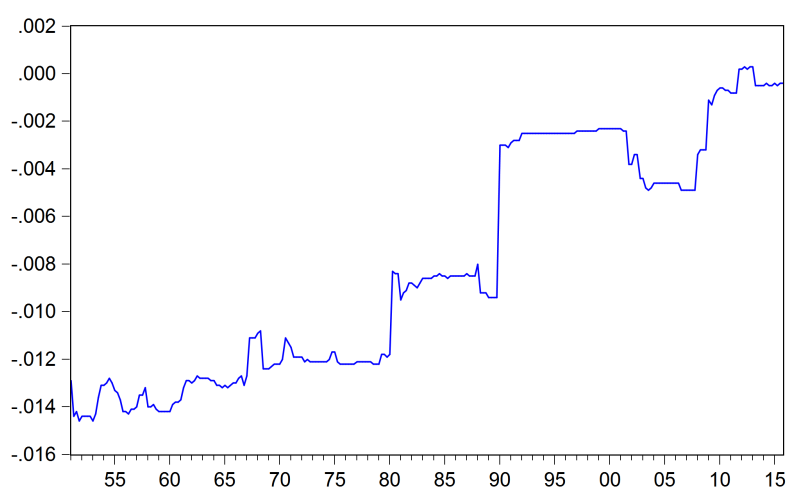

(b) Stock Return (1951-2015)

STOCK_RV_FP_ALL

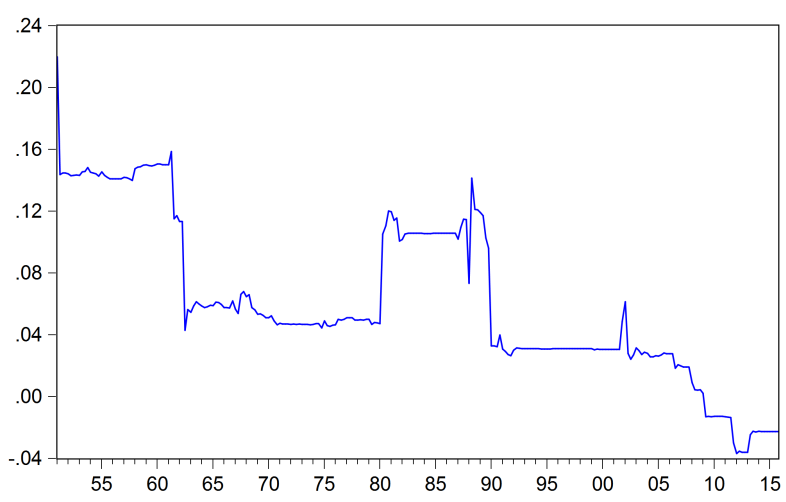

(d) Stock Volatility (1951-2015) 
Figure 4: Time-Varying Impact of Fiscal Policy on the Components of Stock Market volatility

The figures show the time-varying impact of fiscal policy on good and bad components of the stock market volatility.

STOCK_RVG_FP_ALL

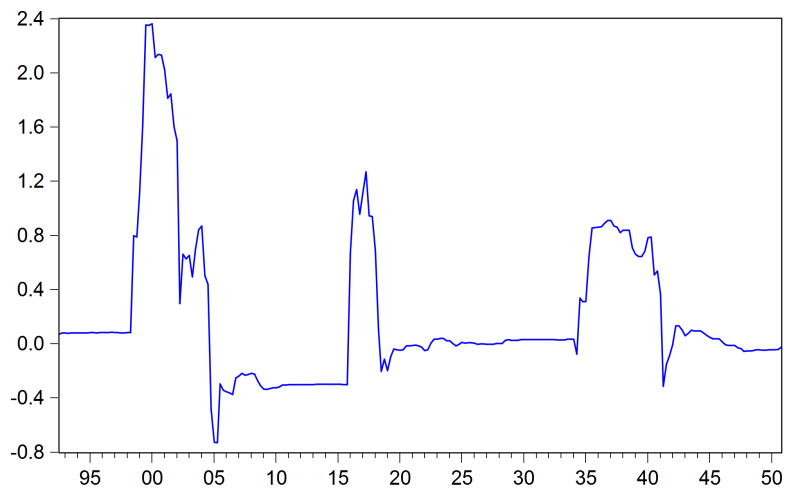

(a) Stock Volatility Good (1890-1950)

STOCK_RVB_FP_ALL

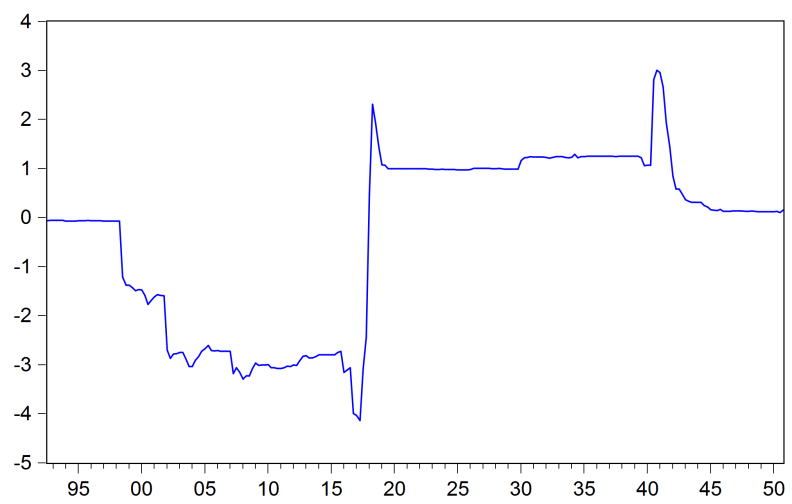

(c) Stock Volatility Bad (1890-1950)
STOCK RVG FP ALL

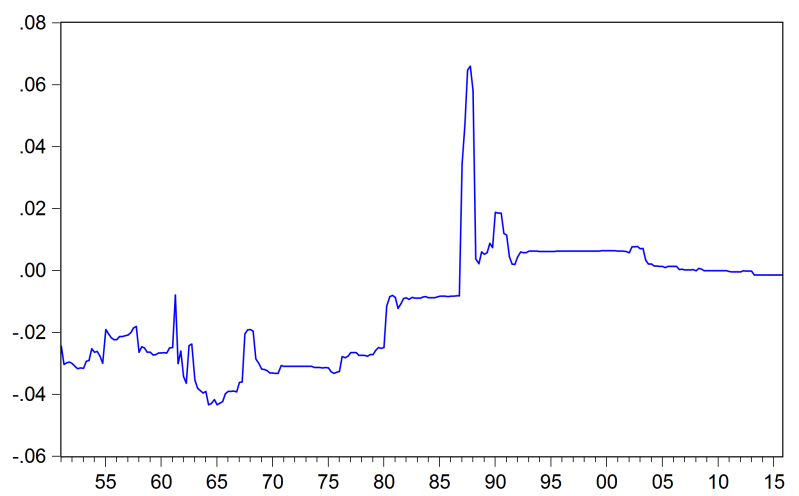

(b) Stock Volatility Good (1951-2015)

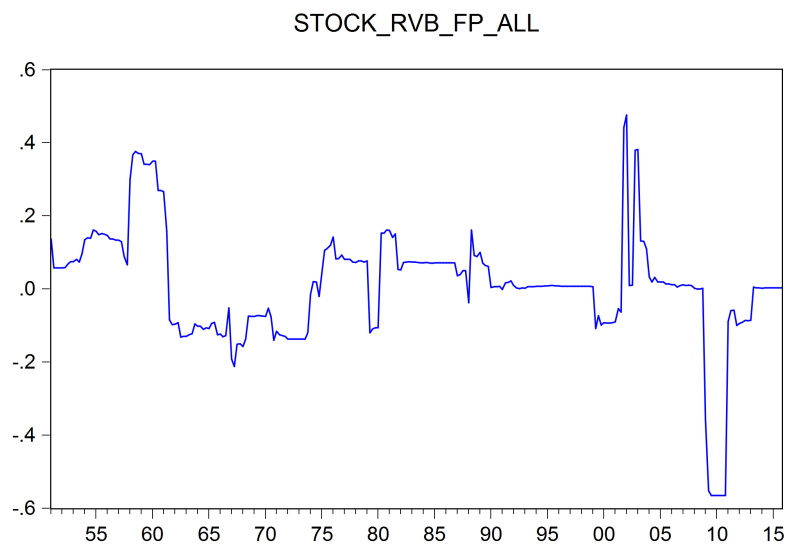

(d) Stock Volatility Bad (1951-2015) 


\section{Appendix A: Analysis of Positive Fiscal Policy Shocks}

Figure 1: Time-Varying Impact of Positive Fiscal Policy Shocks on Bond Market

The figures show the time-varying impact of fiscal policy on the bond market returns and realized volatility.

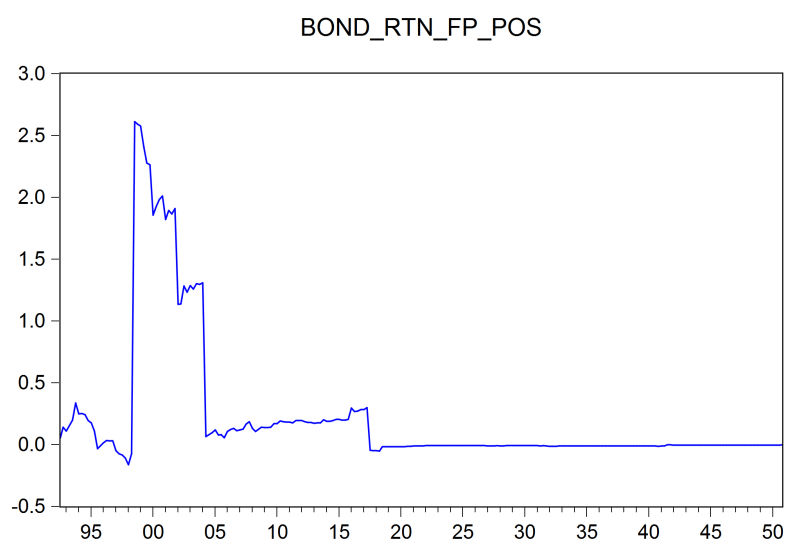

(a) Bond Return (1890-1950)

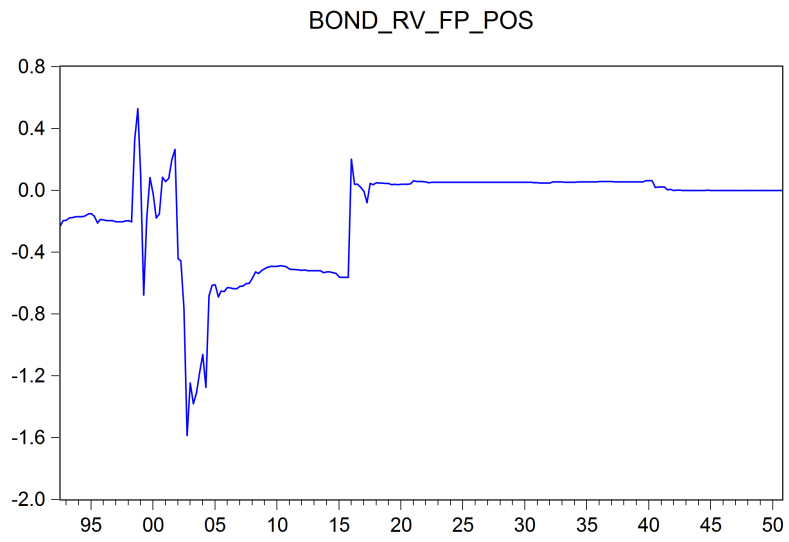

(c) Bond Volatility (1890-1950)

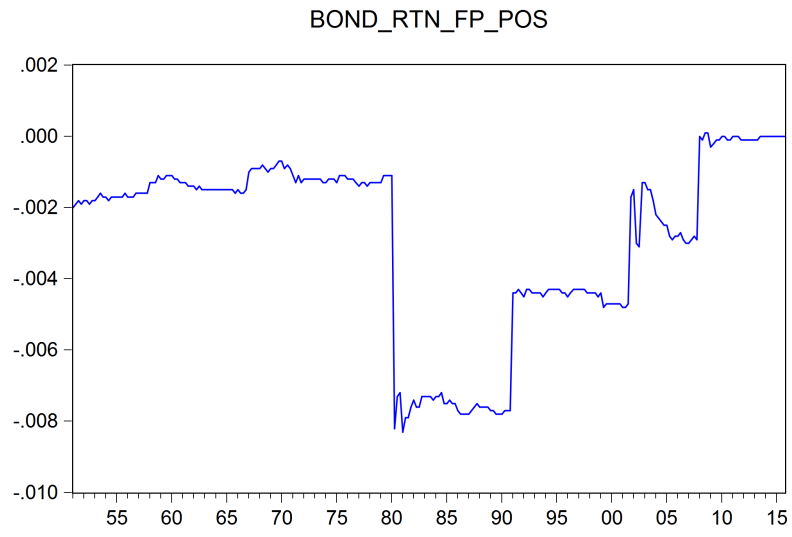

(b) Bond Return (1951-2015)

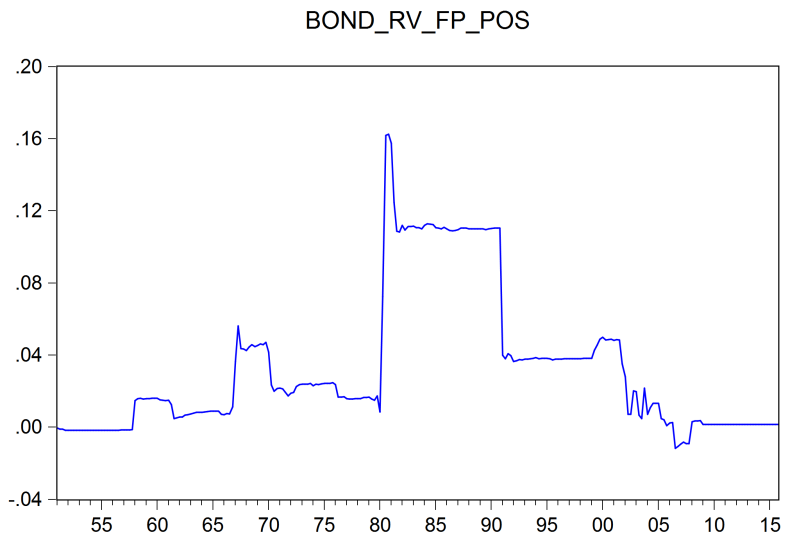

(d) Bond Volatility (1951-2015) 
Figure 2: Time-Varying Impact of Positive Fiscal Policy Shocks on the Components of Bond Market volatility

The figures show the time-varying impact of Fiscal Policy on good and bad components of the bond market volatility.

BOND_RVG_FP_POS

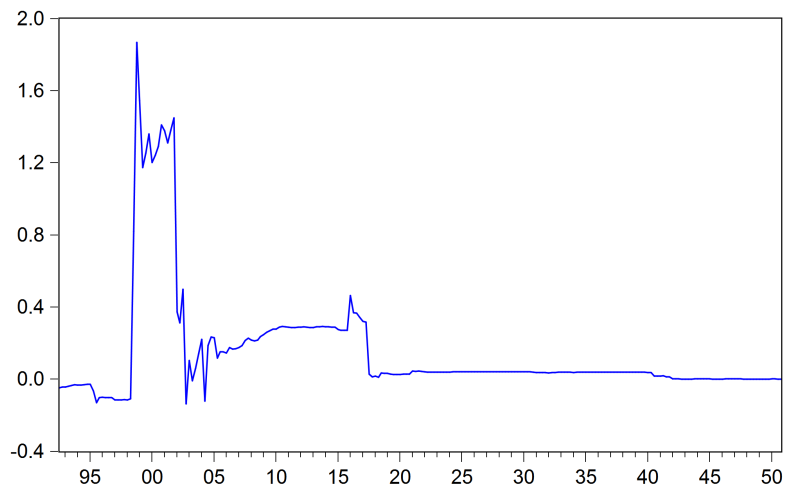

(a) Bond Volatility Good (1890-1950)

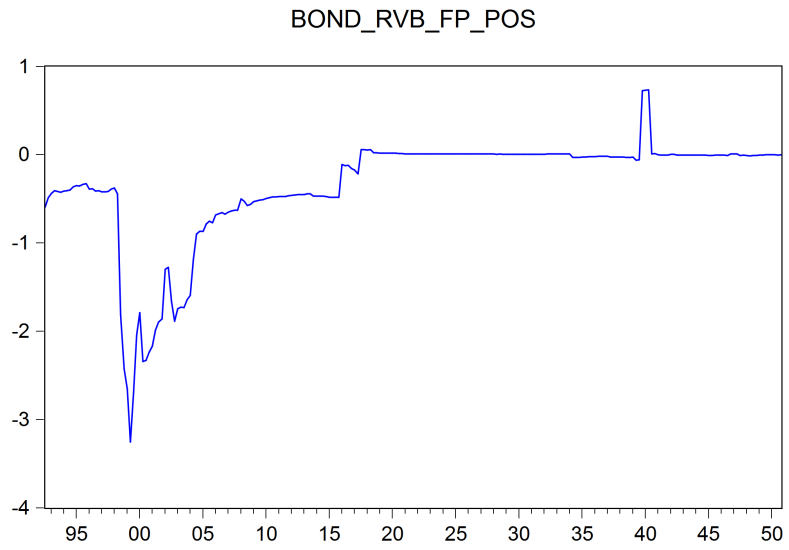

(c) Bond Volatility Bad (1890-1950)

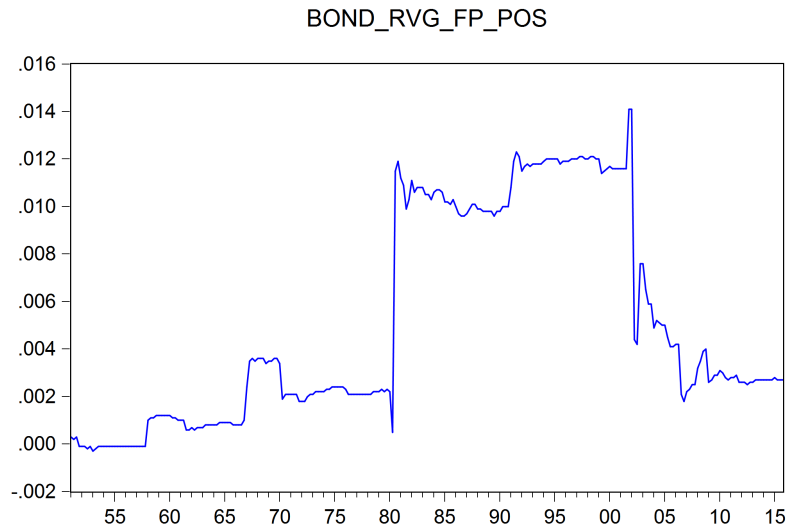

(b) Bond Volatility Good (1951-2015)

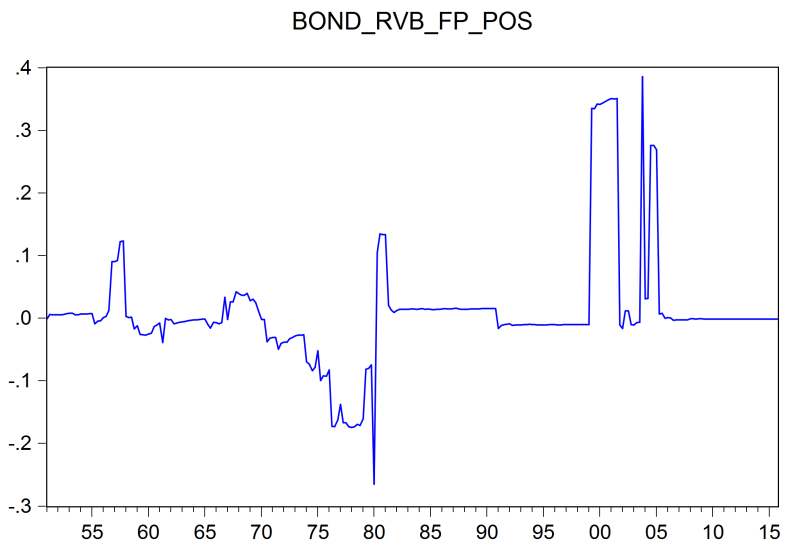

(d) Bond Volatility Bad (1951-2015) 
Figure 3: Time-Varying Impact of Positive Fiscal Policy Shocks on Stock Market

The figures show the time-varying impact of fiscal policy on the Stock market returns and realized volatility.

STOCK_RTN_FP_POS

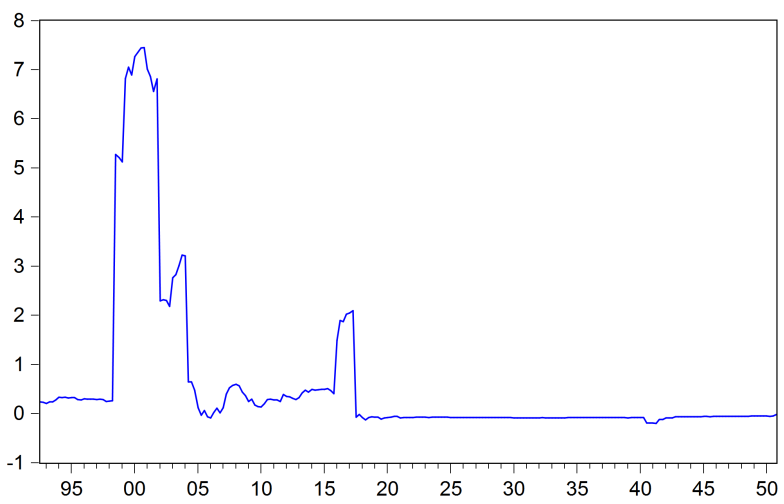

(a) Stock Return (1890-1950)

STOCK_RV_FP_POS

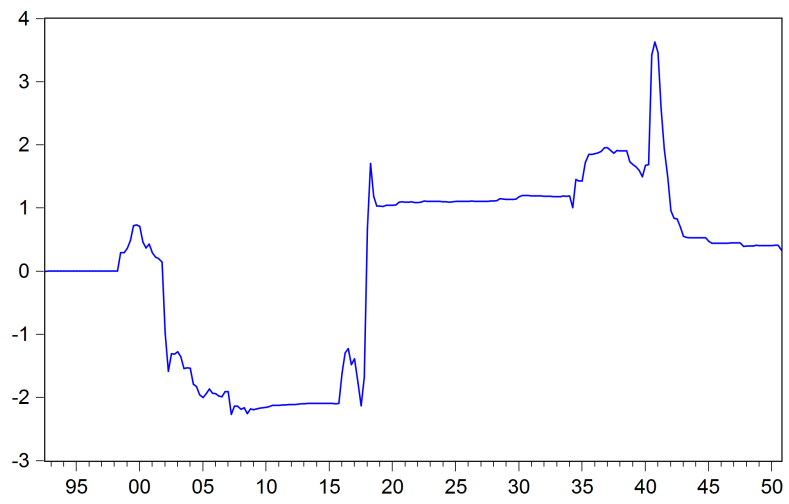

(c) Stock Volatility (1890-1950)
STOCK_RTN_FP_POS

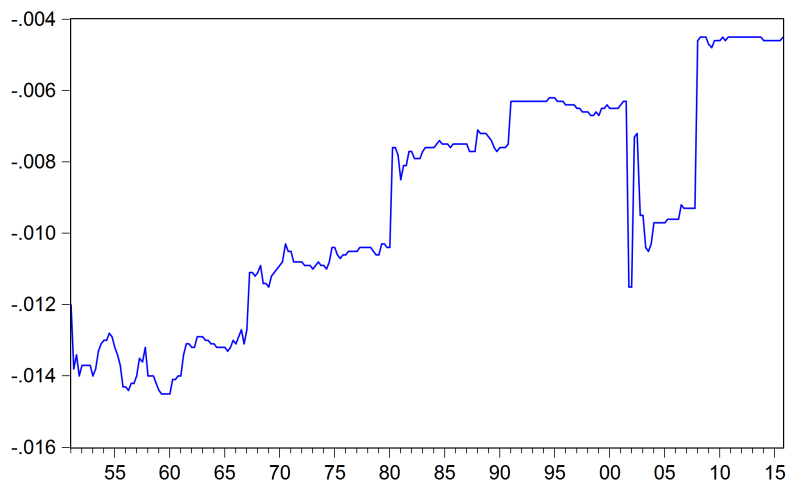

(b) Stock Return (1951-2015)

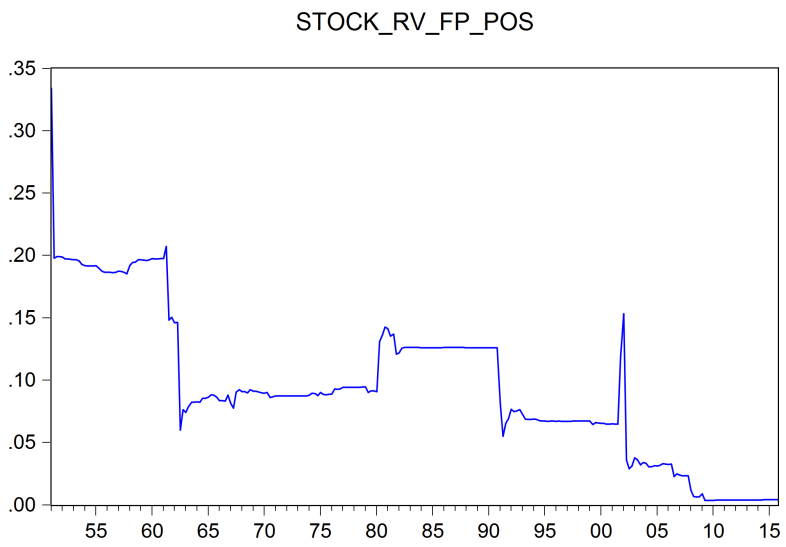

(d) Stock Volatility (1951-2015) 
Figure 4: Time-Varying Impact of Positive Fiscal Policy Shocks on the Components of Stock Market volatility

The figures show the time-varying impact of Fiscal Policy on good and bad components of the stock market volatility.

STOCK_RVG_FP_POS

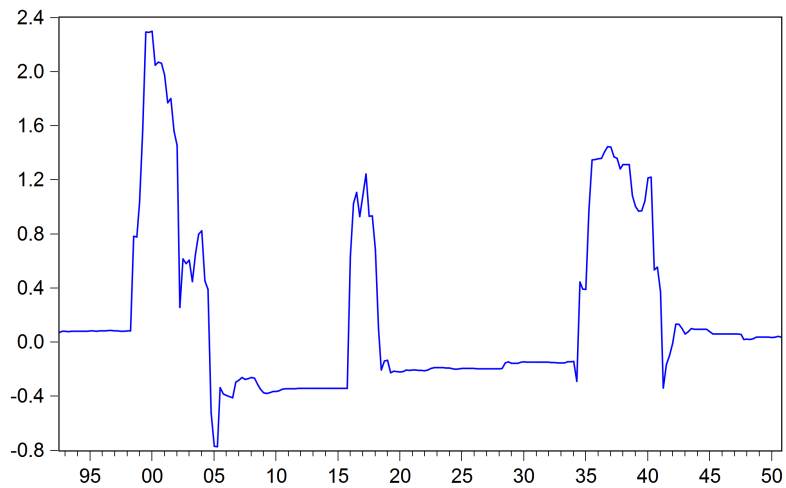

(a) Stock Volatility Good (1890-1950)

STOCK_RVB_FP_POS

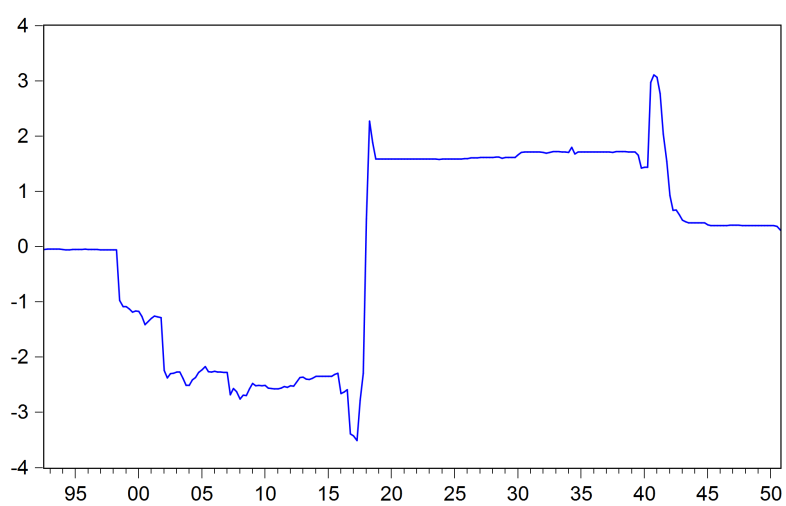

(c) Stock Volatility Bad (1890-1950)
STOCK_RVG_FP_POS

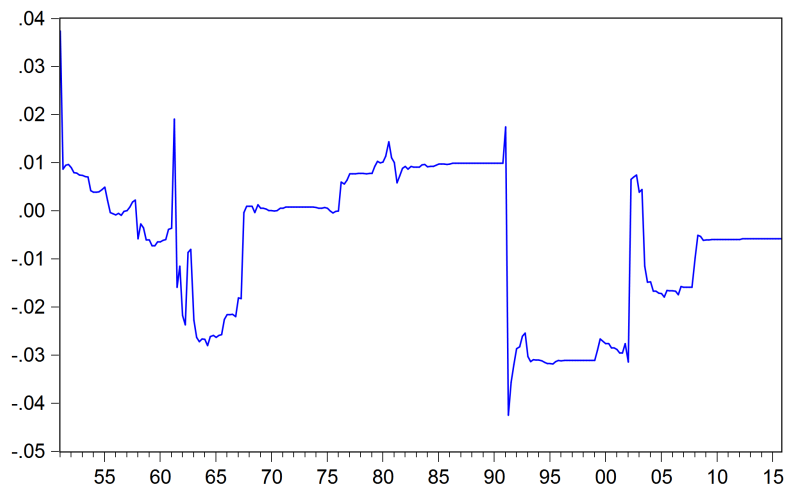

(b) Stock Volatility Good (1951-2015)

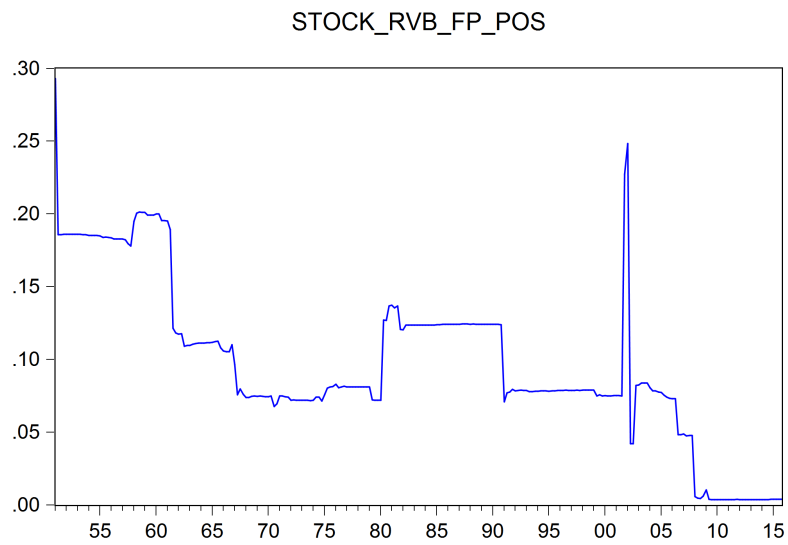

(d) Stock Volatility Bad (1951-2015) 


\section{Appendix B: Analysis of Negative Fiscal Policy Shocks}

Figure 1: Time-Varying Impact of Negative Fiscal Policy Shocks on Bond Market

The figures show the time-varying impact of negative fiscal policy shocks on the bond market returns and realized volatility.

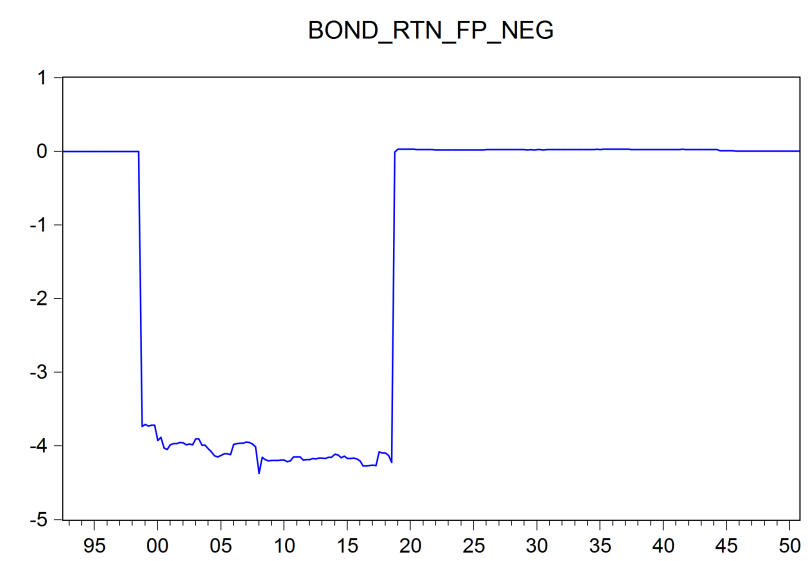

(a) Bond Return (1890-1950)

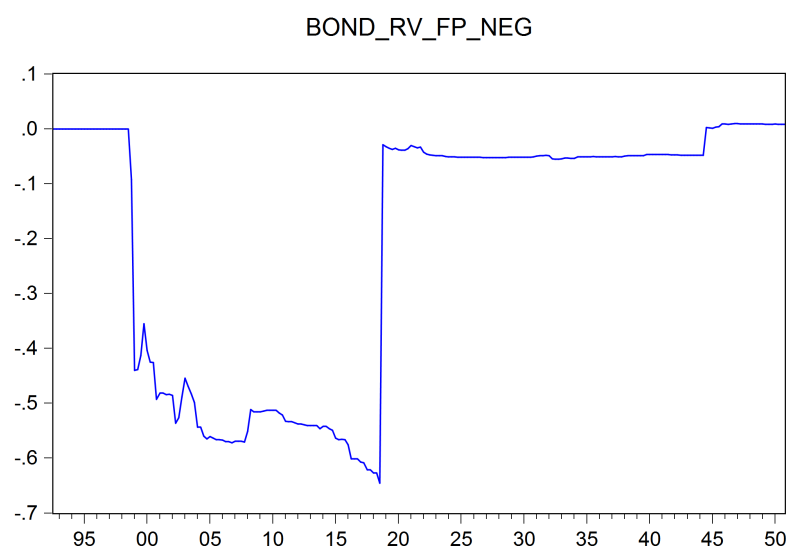

(c) Bond Volatility (1890-1950)

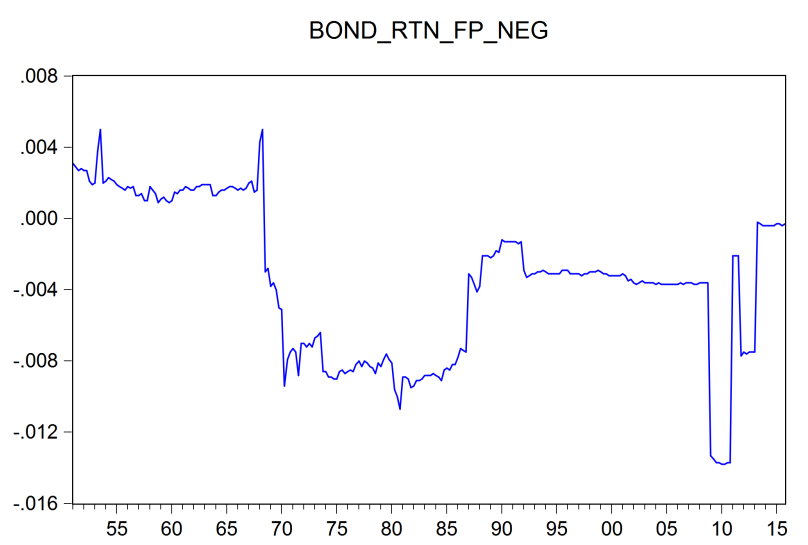

(b) Bond Return (1951-2015)

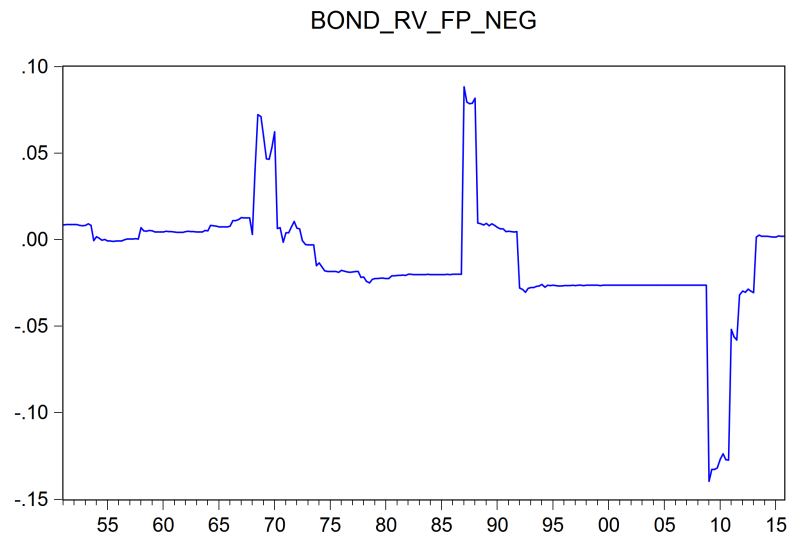

(d) Bond Volatility (1951-2015) 
Figure 2: Time-Varying Impact of Negative Fiscal Policy Shocks on the Components of Bond Market volatility

The figures show the time-varying impact of negative fiscal policy shocks on good and bad components of the bond market volatility.

BOND_RVG_FP_NEG

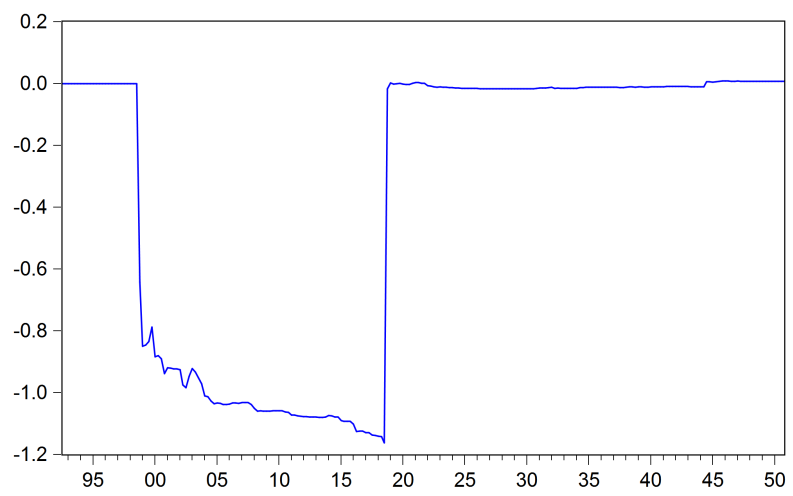

(a) Bond Volatility Good (1890-1950)

BOND_RVB_FP_NEG

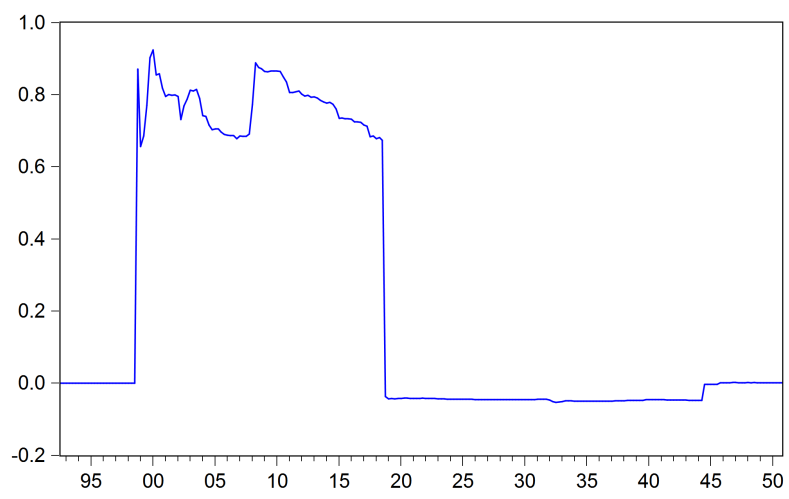

(c) Bond Volatility Bad (1890-1950)
BOND_RVG_FP_NEG

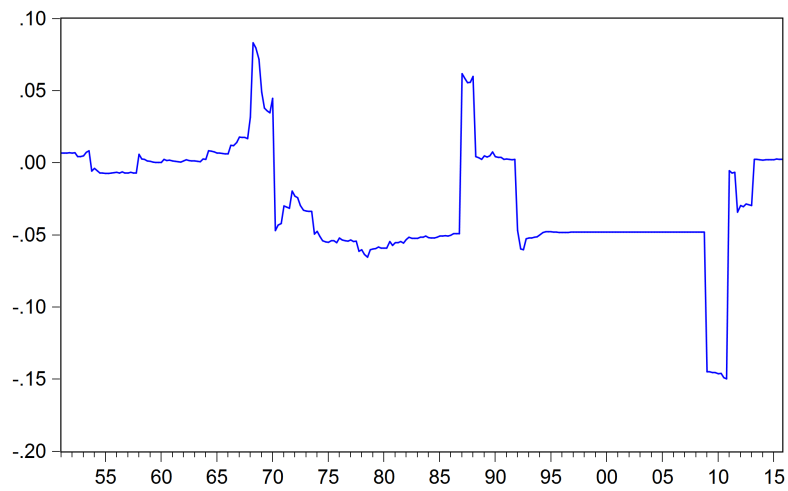

(b) Bond Volatility Good (1951-2015)

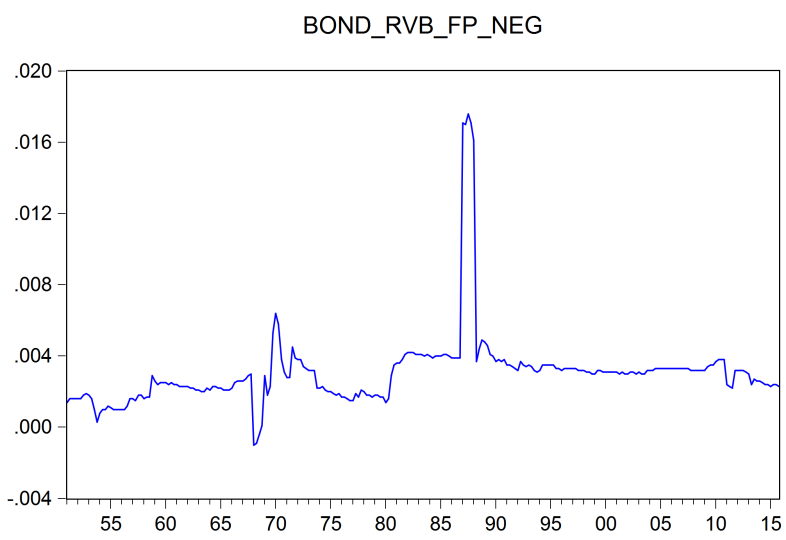

(d) Bond Volatility Bad (1951-2015) 
Figure 3: Time-Varying Impact of Negative Fiscal Policy Shocks on Stock Market

The figures show the time-varying impact of negative fiscal policy shocks on the Stock market returns and realized volatility.

STOCK RTN FP NEG

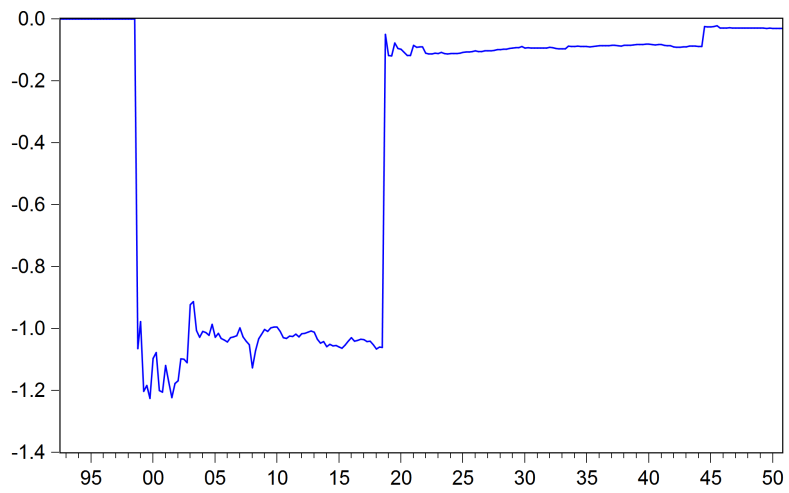

(a) Stock Return (1890-1950)

STOCK_RV_FP_NEG

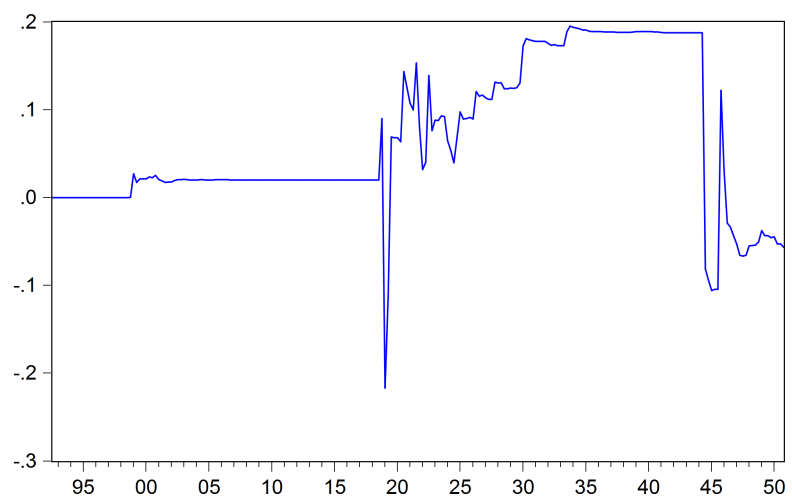

(c) Stock Volatility (1890-1950)
STOCK_RTN_FP_NEG

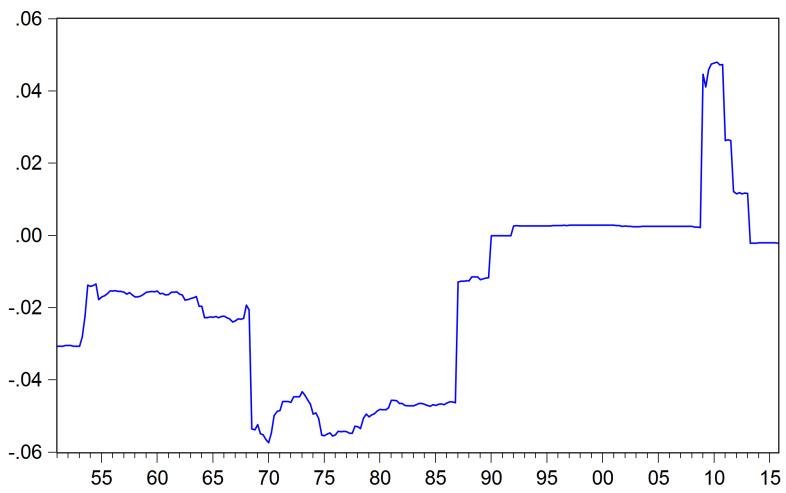

(b) Stock Return (1951-2015)

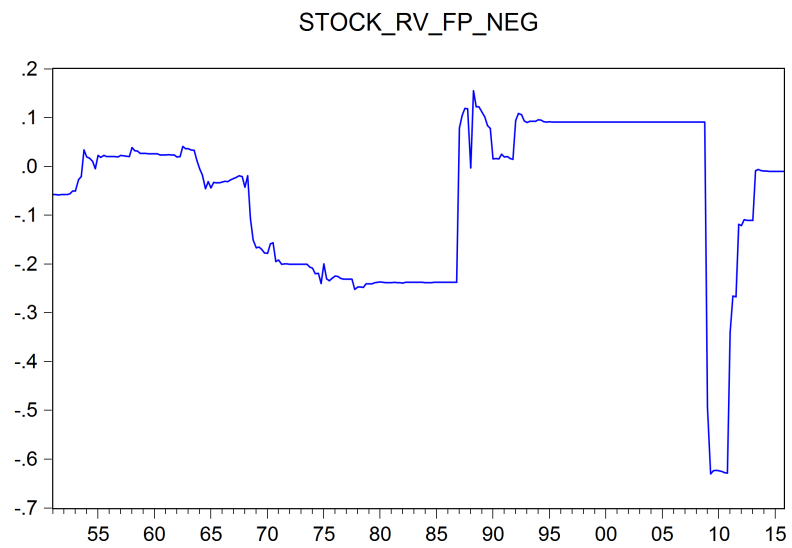

(d) Stock Volatility (1951-2015) 
Figure 4: Time-Varying Impact of Negative Fiscal Policy Shocks on the Components of Stock Market volatility

The figures show the time-varying impact of negative fiscal policy shocks on good and bad components of the stock market volatility.

STOCK_RVG FP NEG

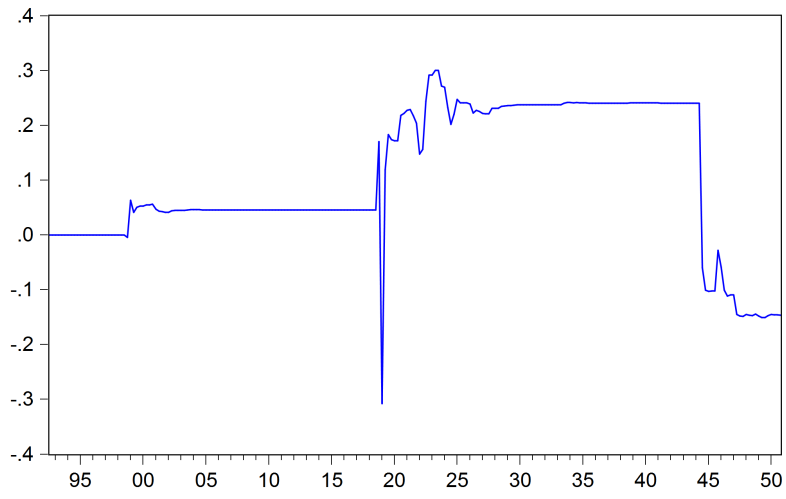

(a) Stock Volatility Good (1890-1950)

STOCK_RVB_FP_NEG

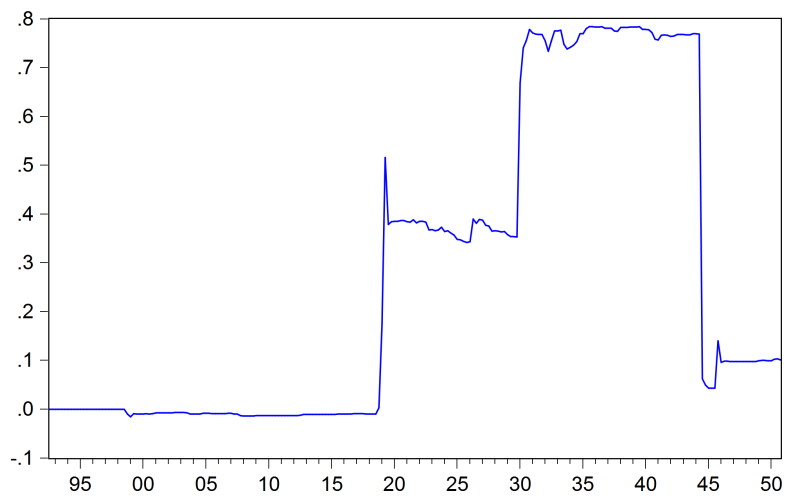

(c) Stock Volatility Bad (1890-1950)

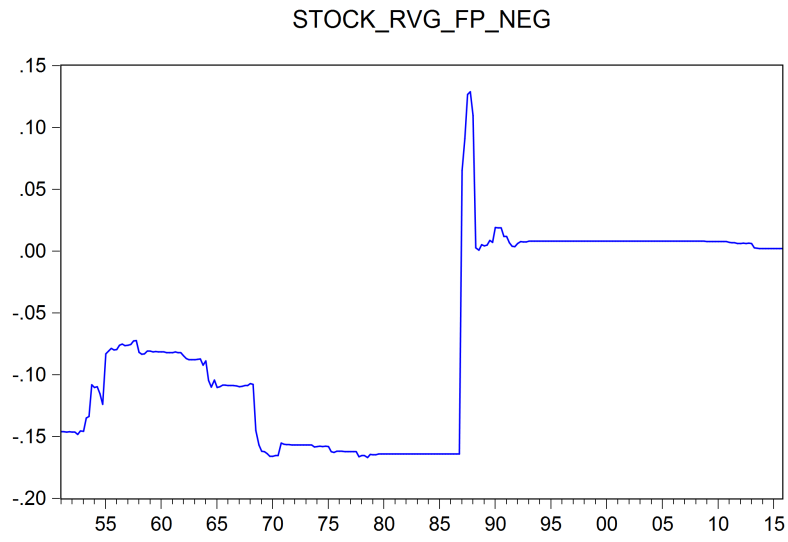

(b) Stock Volatility Good (1951-2015)

STOCK_RVB_FP_NEG

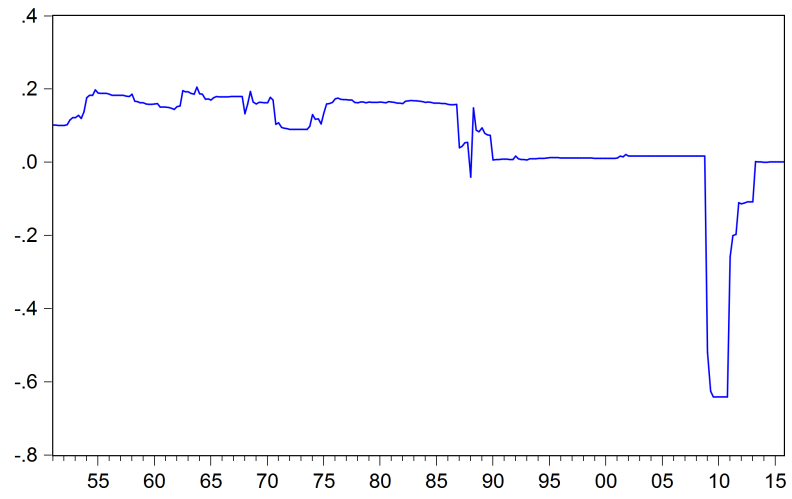

(d) Stock Volatility Bad (1951-2015) 